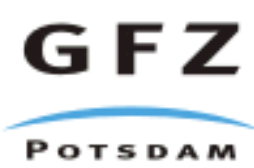

Originally published as:

Frischbutter, A., Hanisch, M. (1991): A model of granitic melt formation by frictional heating on shear planes. - Tectonophysics, 194, 1-2, 1-11

DOI: 10.1016/0040-1951(91)90268-W. 


\title{
A model of granitic melt formation by frictional heating on shear planes
}

\author{
Alexander Frischbutter ${ }^{a}$ and Mathias Hänisch ${ }^{b}$ \\ ${ }^{a}$ Central Institute of Physics of the Earth, Telegrafenberg, Potsdam 0-1561, FRG \\ ${ }^{b}$ University of Technology Dresden, Leubnitzer Strasse 3, Dresden, 0-8010, FRG
}

(Received October 12, 1990; revised version accepted February 15, 1991)

\begin{abstract}
Frischbutter, A. and Hänisch, M., 1991. A model of granite melt formation by frictional heating on shear planes, Tectonophysics, 194: 1-11.

Based on geological data derived from structural investigations in the field a hypothesis of anatexite formation along shear planes by frictional heating is proposed. The hypothesis involves a physico-mathematical model which was tested for different mechanisms and by numerical calculations with different parameters. The formation of frictionites (melt rocks) of small volumes $\left(\mathrm{m}^{3}\right)$ requires a depth of deformation in the crust of more than $5 \mathrm{~km}$ and a particular tectonic regime and should be possible on the assumption of a stick-slip process in association with a trigger mechanism of source activation. The thermodynamical model employed needs further verification from the mechanical and material points of view.
\end{abstract}

\section{Introduction}

The Variscan belt in central Europe is marked by a widespread pre-Variscan, early Paleozoic magmatism, which reflects reactivation of the crust, but is not associated with structure forming processes; there is little to no evidence of Caledonian tectogenesis.

This paper deals with a particular aspect of the granitoid part of the magmatism, which was named "Rotgneis" by the Erzgebirgian silver miners. "Rotgneis" includes suites of gneisses of widely different orogins. There are gneisses derived from intrusive (and extrusive?) granitic magmas, blastomylonites, metasomatic rocks in connection with particular structures, and anatexites resulting from later processes of deformation under particular conditions. Although the term "Rotgneis" should be abandoned, it is probably permanently entrenched in the geological literature of the Erzgebirge and central Europe in general.

A model is presented for the genesis of the anatexites mentioned above, which may be of general significance in the Palaeozoic evolution of the Saxothuringian zone of the Central European Variscides.

\section{Geological background}

The description by Scheumann (1938) of the "Rotgneis" within the Upper Proterozoic crystallines of the Erzgebirge anticlinorium at the northern border of the Bohemian massif as orthogneisses includes the occurrence of nearly untextured, medium- to coarse-grained granitoids. Scheumann (1938) called them "Reliktgranit" (relict granite) and considered them as accidental unmetamorphosed remnants of the original intrusive parent rock.

Results of recent investigations-small-scale geological mapping (Frischbutter, 1982, 1985); geochemical investigations (Frischbutter and Just, 1988); thermobarometric studies (Frischbutter et al., 1989)-suggest a genetic model which explains these "Reliktgranite" by generation of granitoid (restitic) melts along flat-dipping shear planes by frictional heating.

The rocks are deformed into folds with strong 
southern vergency, a wavelength of 1 up to $2 \mathrm{~km}$, and ENE-WSW trending axes (Fig. 1). The earlier deformation involved folding of an older crystalline schistosity $\left(s k_{1}\right)$ formed during amphibolite facies metamorphism in early-Palaeozoic times (Frischbutter, 1990). Related to this folding, a younger crystalline schistosity $\left(s k_{2}\right)$ was formed parallel to the axial planes. Further shortening was accommodated by simple shear on the $s k_{2}$ planes, facilitated by the parallelism of $s k_{1}$ and $s k_{2}$ in the turning point zones of the overturned limbs of the folds. The metamorphism related to this deformation was also in amphibolite facies at least, and locally may have reached conditions of granite melt generations; it is probably of early Variscan age (Frischbutter, 1990). The rocks in question were named "frictionites", according to the proposed model of formation.

The most important field relations, from which the model is derived, are:

(1) String-of-beads-like distribution of the lenses of frictionite parallel to the axes of the $s k_{1}$-folds. The particular structural position is further indicated by features such as predominant $s k_{2}$-planes associated with microfolded $s k_{1}$-planes adjacent to the frictionites.

(2) Generally the frictionites are separated from country (parent) rock by a narrow zone of transitional gneiss (Übergangsgneis), characterized by a cataclastic-mylonitic fabric and the occurrence of kyanite, which is found only here (indicating high pressure conditions).

\section{GEOLOGICAL MODEL}

\section{GEOLOGICAL MAP}
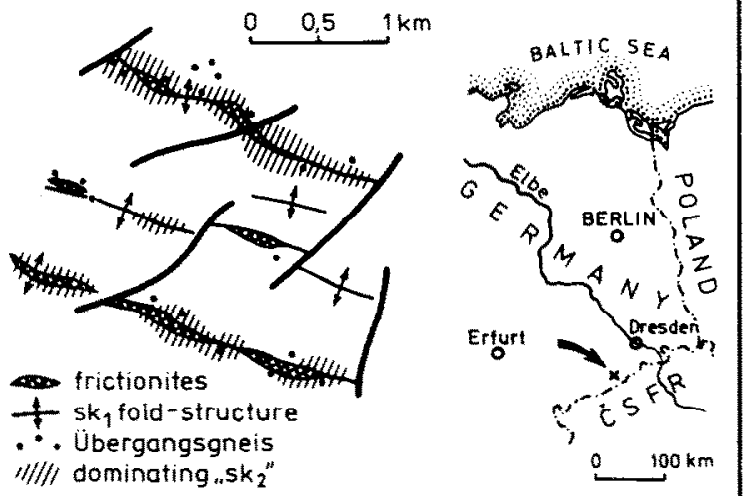

\section{CROSS SECTION}

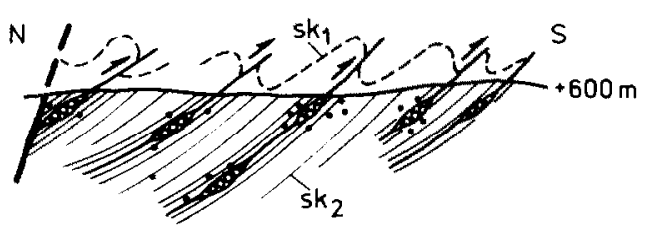

MODEL

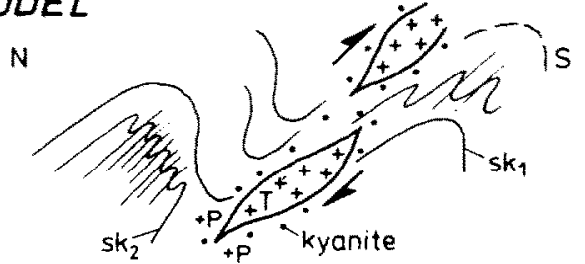

\section{MATERIAL EVOLUTION}

\section{MINERAL AND TRACE ELEMENTS}

potosh feldspar, plagioclase

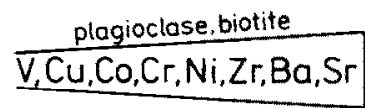

Innerer Rotgneis $\rightarrow$ Übergangsgneis-frictionite
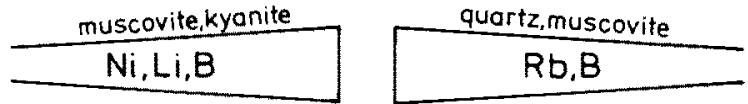

\section{RARE EARTH ELEMENTS}

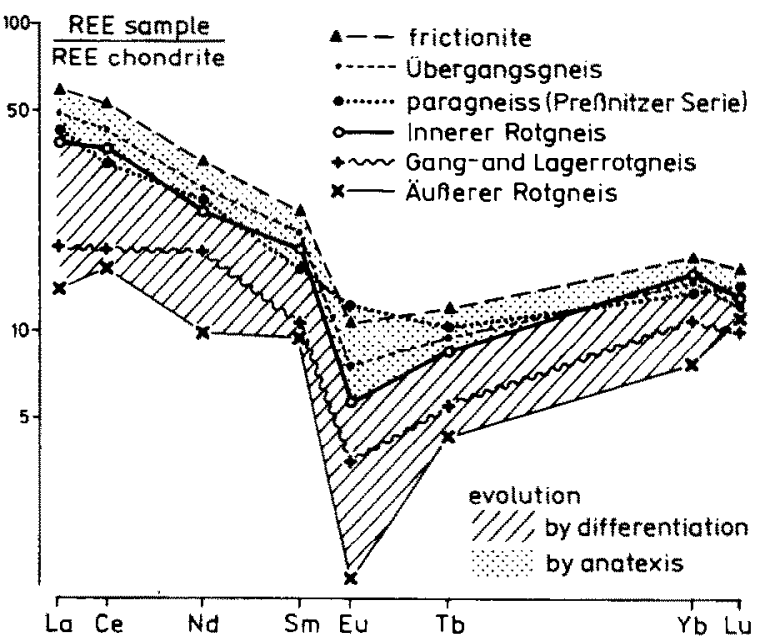

Fig. 1. The geological model expressed by a schematic geological map, a cross section and characteristics of the geochemical evolution $\left(s k_{1}=\right.$ older-, $s k_{2}=$ younger crystalline schistosity $)$. 


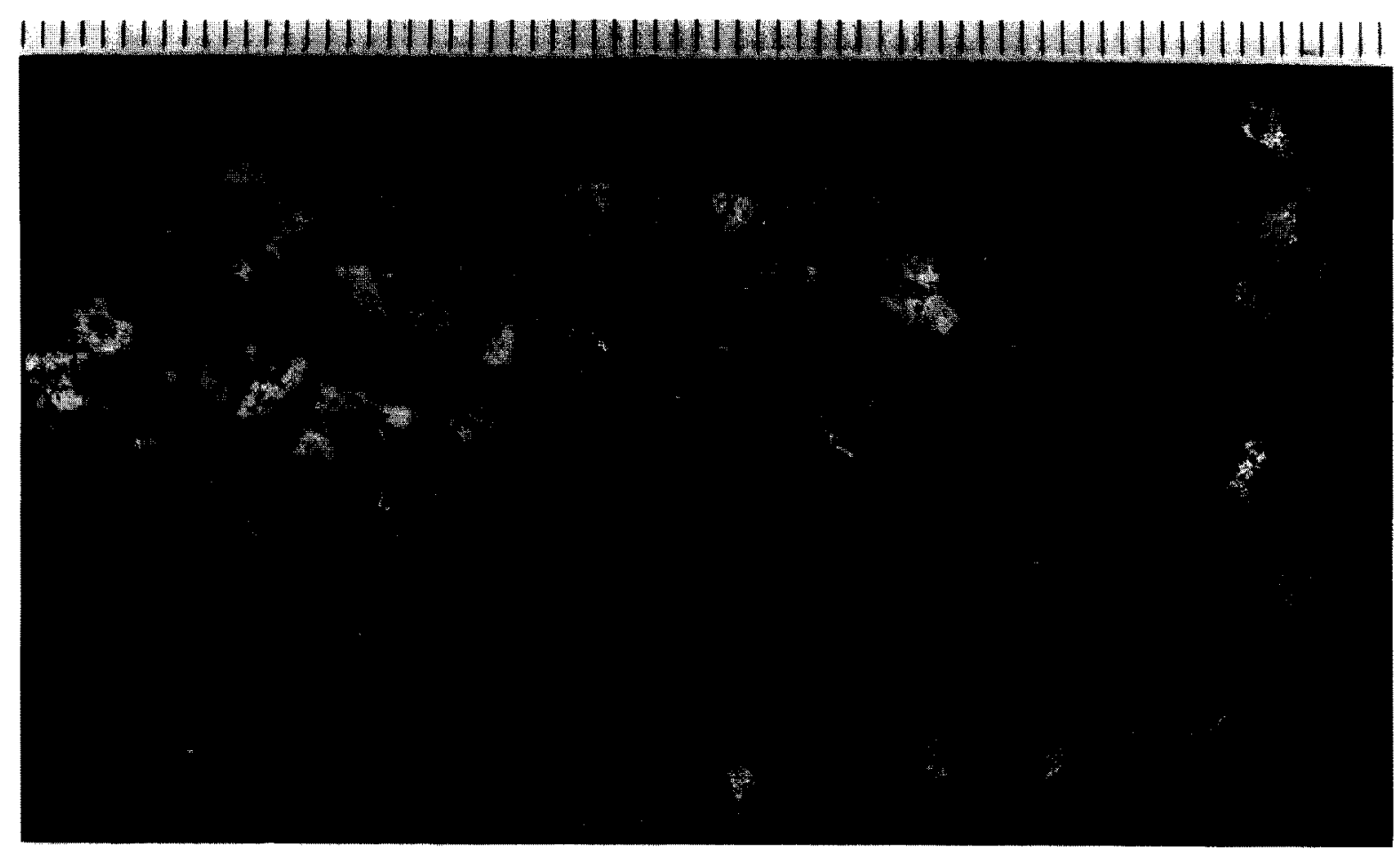

Fig. 2. Frictionite, derived from the parent rock "Innerer Rotgneis" (scale in millimetres).

(3) The thickness of the frictionite bodies is small: at most $10 \mathrm{~m}$ (maximum) in a belt of lenses extending a few hundred metres.
(4) The frictionites were derived from different types of parent rocks (orthogneisses as well as paragneisses). They are a typical feature of the

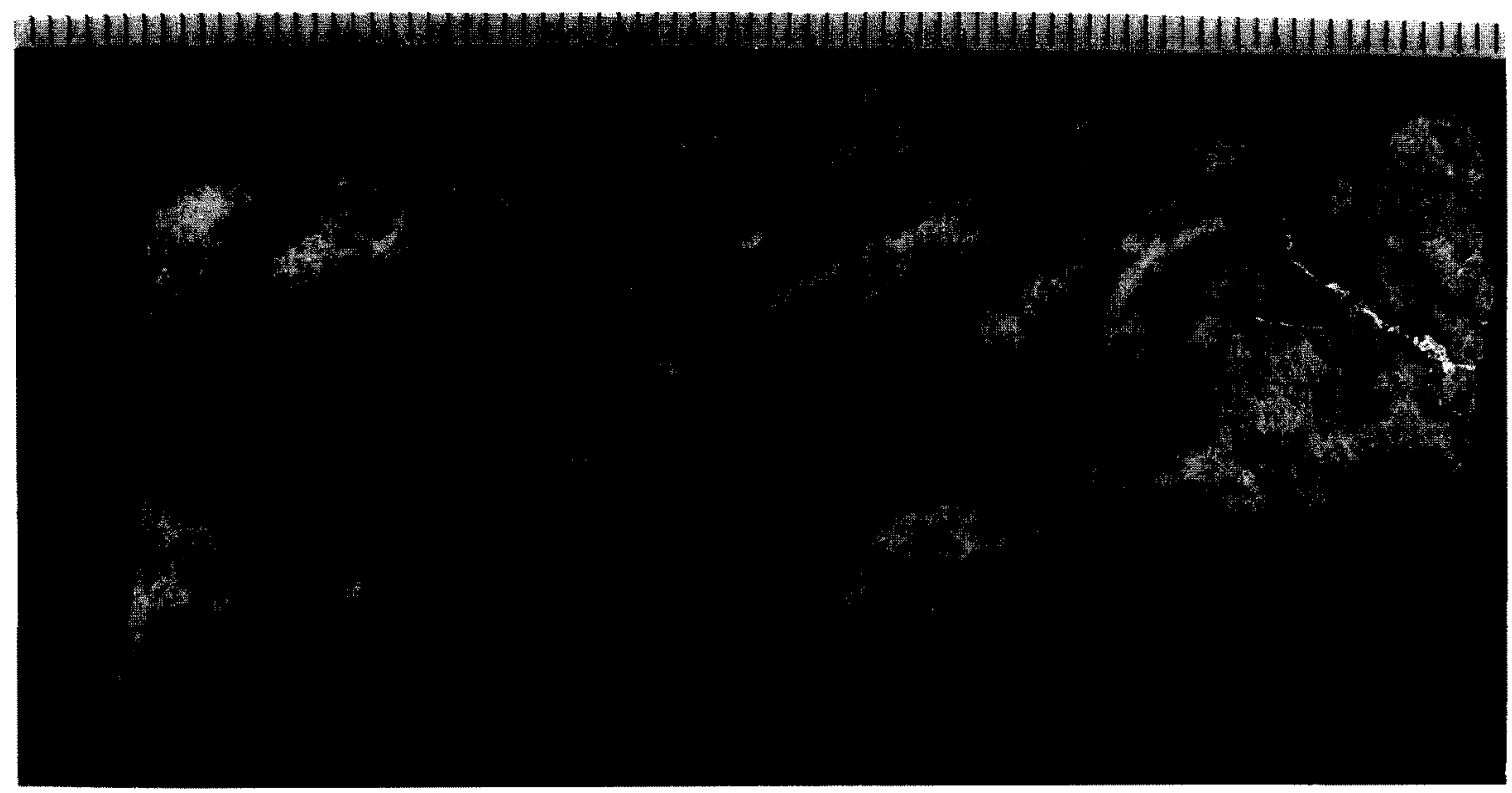

Fig. 3. "Innerer Rotgneis" (scale in millimetres). 
core of, for example, the Reitzenhainer Rotgneisstructure (middle Erzgebirge Mts., southeast Germany). At the same structural position where deformation was lower in the more pheripheric parts of the Reitzenhain complex, the frictionites are replaced by pencil gneisses (R-tectonites). Formation of these rocks depends on the level of deformation in the Earth's crust: frictionites are thought to have developed at more than 5 to 10 $\mathrm{km}$ depth, R-tectonites at less or about $5 \mathrm{~km}$ only. The frictionites are coarse grained, and almost untextured. Only locally are traces of a relict schistosity preserved (Figs. 2 and 3).

Petrographic characteristics are the commonly pale blue quartz, the red-brown, fresh biotite (the dominant mica) and the "nest-like" concentration of mica (Frischbutter, 1982, 1985). To verify this field-derived hypothesis a mathematical-physical model was formulated and tested as described below.

\section{The general model}

The problem under investigation became evident in connection with studies concerning the geotcctonic position of the pre-Variscan orthogneisses at the northern border of the Bohemian massif, in particular the Reitzenhain Rotgneis complex (Erzgebirge). There are no outcrops of frictionites in the Reitzenhain complex within southeast Germany. The only outcrops are situated in Czechoslovakia (ČSFR) north of Most and have been described by Scheumann (1938). The conditions of formation of frictionites may be assessed by means of mineral facies data on the paragenesis of kyanite, garnet and biotite (Fig. 4).

The problem of frictional heat along shear planes and resulting melt formation has been discussed during recent years by several authors; McKenzie and Brune (1972); Brewer (1981), Pavlis (1986). From geological data Stettner $(1971,1972)$ interpreted the entire laccolithic Rotgneis bodies in the central European Variscides as a product of melting in planar shear zones-a concept physically untenable since, as will be shown here, only small volumina of melt can be generated in this way.

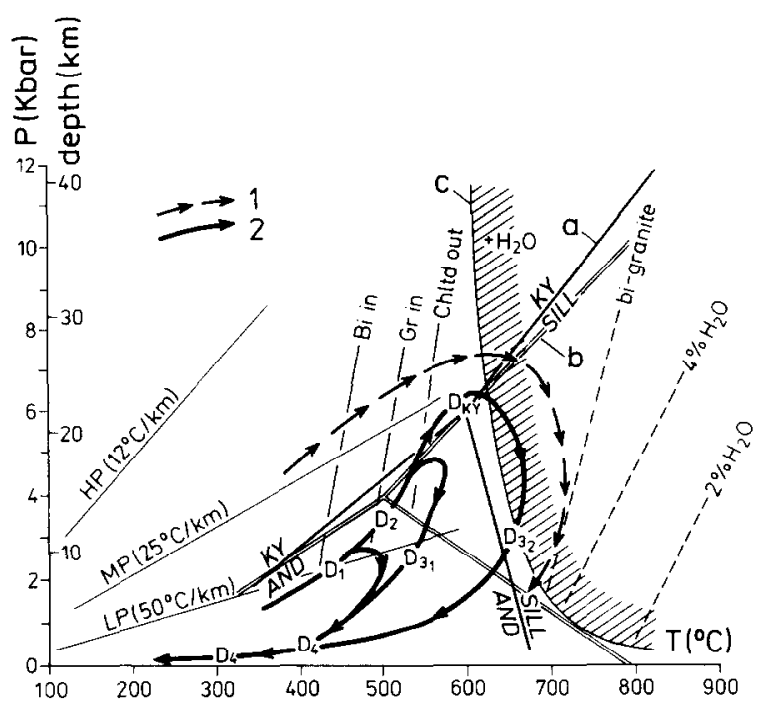

Fig. 4. Temperature-pressure diagram of metamorphism in the Erzgebirge crystallines from geological data (Frischbutter, 1990). $1=P T$ path, eastern Erzgebirge; $2=P T$ path, western Erzgebirge; $D_{1}-D_{4}=$ stages of metamorphism after thermobarometric data (Frischbutter et al., 1989): $D_{1}=$ ss-folding, $D_{2}=$ formation of $s k_{1}$ under folding of $s_{1} / s k_{0}(?), D_{3}=$ folding of $s k_{1}$ to $s k_{2}, D_{3_{1}}=$ formation of R-tectonite fabrics, $D_{3_{2}}=$ formation of frictionites, $D_{\mathrm{k}}=$ growth of kyanite in the Übergangsgneise (pre-frictionites stage), $D_{4}=$ superimposing $s_{\mathrm{r}}$-fabric formation. Alumosilicate phase relations are from $(a)$ Winkler (1974) and (b) Holdaway (1971), liquidus-solidus relation of granite systems (c) from Luth et al. (1964).

Evaluation of the physico-mathematical aspects of our model are rooted in analytical solutions of the one-dimensional Fourier equation of heat conduction in solids, which, in order to include the melting process itself, have in part been coupled with numerical solutions (McKenzie and Brune, 1972). The advantage of analytical solutions lies in the case in which parameters can be formulated, allowing the delineation of geologically and physically reasonable conditions. On the other hand, numerical solutions of the heat-conduction equation offer high flexibility in the required boundary and initial conditions. In particular, processes of phase change may be included a priori in the formulation. Among useful variations are balanceor difference-procedures and the finite element method.

Although the application of a numerical procedure facilitates a complex solution, the problem of 
deriving a reliable, physical model remains difficult. Fundamental to this subject is:

(1) the connection between the mechanical and thermodynamical models;

(2) knowledge of the temperature dependence of the material properties;

(3) knowledge of the influence of temperature on mechanical material properties.

A rigorous solution can be reached only with a genuine coupling of the thermal and the mechanical behaviour of state.

Within the scope of the present study only a weak coupling of the mechanical and thermodynamical models can be reached. The solution of the problem is founded on the assumptions of the heat source distribution along the shear plane, derived from ideas on the frictional behaviour of the shear planes. This thermodynamic treatment (calculation of the temperature field) allows conclusions to be drawn regarding the mechanical behavior, although only approximate conditions regarding the source distribution can be defined. Necessary conditions in the sense of point (3) cannot be derived by these means. Therefore the following difficulties arise:

(a) It follows from simple one-dimensional estimates of temperature profiles (sec also McKenzie and Brune, 1972; Pavlis, 1986) that "stable gliding" at low displacement velocities $(\mathrm{cm} / \mathrm{yr})$ can be excluded as a possible mechanism for reaching the temperature required for melting. To attain the melting temperature, geologically unrealistically large displacements must be invoked.

(b) A stick-slip mechanism, as discussed in connection with earthquakes (Ohnaka, 1978), results in very short times to attainment of melting temperatures. Heat release will be shock-like and the temperature wave will penetrate only to shallow depth, due to the poor thermal conductivity of the rock. Only melt zones of millimetre scale would result (McKenzie and Brune, 1972).

Besides, with the first formation of melts, the heat generated by friction would be strongly reduced, thus quickly bringing the process to an end. Physically based formulations regarding the magnitude of the source intensity after reaching of melting can not be given.

(i) If the energy release is not planar but is absorbed in a zone of plastic deformation, melting conditions can not be reached over widths in the range of centimetres.

(ii) The geologically evident examples of meter-thick frictionites might be explained, with regard to the foregoing, as follows: The model requires many relatively closely spaced surfaces, that are simultaneously or slightly temporally staggered acting as shear planes in a stick-slip process. The stress release occurs in cascade fashion whereby melting must be controlled by a trigger mechanism and an activation of suitable, neighboring shear planes. The thickness of the molten sheet is determined by the energetically favourable part of the vergent fold structure, where the folded (older) and the newly formed (younger) schistosities are parallel to each other orientated (inflection point region within the overturned limb of the fold).

(iii) The latter mentioned hypothesis, drawn entirely from thermodynamic considerations, needs further verification from the mechanical standpoint. We can only draw conclusions concerning the thermodynamically required source distribution from temperature profiles, derived from calculations with different parameters. A genuine coupling in the sense of point (3) is not obtained.

\section{The physical model}

\section{Basic equations}

Temperature propagation in solids is described by the Fourier equation. Its general form reads:

$\rho c \frac{\partial T}{\partial t}+\rho c v \operatorname{grad} T=\operatorname{div} \lambda \operatorname{grad} T+\dot{q}(\boldsymbol{r}, t)$

The solution of eqn. (1) has to satisfy initial conditions:

$T(\boldsymbol{r}, t=0)=f_{1}(\boldsymbol{r})$

and boundary conditions:

$n \lambda \operatorname{grad} T \mid \boldsymbol{r}_{\mathrm{B}}=f_{2}\left(T, t, \boldsymbol{r}_{\mathrm{B}}\right)$

In eqns. (1)-(3) the symbols are defined as follows: $\rho=$ density, $c=$ specific heat capacity, $\lambda=$ thermal conductivity, $\dot{q}=$ source intensity, $t=$ 
time, $T=$ temperature, $v=$ velocity, $n=$ normal vector, $\boldsymbol{r}=$ space vector, and index $B=$ boundary. Further we have as a starting point the two-dimensional Cartesian model:

$$
\begin{aligned}
\rho c \frac{\partial}{\partial t} T(x, y, t)= & \frac{\partial}{\partial x} \lambda x \frac{\partial T}{\partial x}+\frac{\partial}{\partial y} \lambda y \frac{\partial T}{\partial y} \\
& +\dot{q}(x, y, t)
\end{aligned}
$$

where the convective term $v$ grad $T$ is neglected. (Consideration of this term yields additional numerical complications but not qualitatively different conclusions, as it merely implies a distortion of the temperature field in the direction of motion.)

\section{Model of source distribution}

The surfical energy release by friction on shear planes is given by te relation:

$\dot{q}(x, y, \iota, T)=\eta(x, y, t, T) \bar{v} \sigma$

where $\eta=$ efficiency of conversion of mechanical into thermal energy for $0 \leq \eta \leq 1, \bar{v}=$ mean velocity of displacement, and $\sigma=$ shear stress.

The mean slip velocity for a stick-slip event is given, after Aki (1979), by:

$v=\frac{2}{\nu} \frac{\Delta \sigma}{\rho^{2} \beta}$

where $\Delta \sigma=$ shear stress decrease, $\beta=$ velocity of shear waves, and $\nu=$ numerical constant. Substituting eqn. (6) into eqn. (5) gives the heat source distribution in terms of physical parameters and a heuristic function $\eta(x, y, t, T)$ :

$\dot{q}(x, y, t, T)=\eta(x, y, t, T) \frac{2}{\nu} \frac{\Delta \sigma \cdot \sigma}{\rho^{2} \beta}$

Introducing the efficiency factor $\eta$ permits modelling the dependence of temperature, time and space on the source distribution:

$\eta(x, y, t, T)=\epsilon(T, t) \cdot \omega(x, y)$

where $\epsilon$ is the temperature-time-dependent term and $\omega$ is the space-dependent term.

The following algorithms are applied: a surface plane $\left(\Delta x_{0}, \Delta y_{0}\right)$ is retained by a surface source up to the attainment of temperature $T_{\mathrm{I}}$ (regime $\mathrm{I}$ : $\left.t \leq t_{\mathrm{ph}}\right)$. The subsequent regime II $\left(t \geq t_{\mathrm{ph}}\right)$ allows the following variations and combinations respectively:

(a) The source will be reduced by the constant factor $\epsilon_{I I}\left(0 \leq \epsilon_{I I} \leq 10^{-3}\right)$. In the case of values below $T_{1}, \epsilon_{1}$ will be used again.

(b) The next surface $\left(\Delta x_{1}, \Delta y_{1}\right)$ will be activated.

The temperature dependence in regime $I$ is simulated by the following formulations:

$\epsilon_{\mathrm{i}}(T)\left\{\begin{array}{l}=1 \\ =\frac{1}{a+b T} \\ =c_{1} \exp \left(c_{2} / T\right) \\ =\frac{T_{1}-T}{T_{1}-T_{0}}\end{array}\right.$

whereby the constants are determined from the conditions of the initial temperature $T_{0}$ :

$\epsilon_{\mathrm{I}}\left(T_{0}\right)=1$

and the temperature $T_{\mathrm{l}}$ :

$\epsilon_{1}\left(T_{\mathrm{I}}\right)=\epsilon_{\mathrm{II}}$

\section{Determination of the phase transition}

Determination of the phase transition is accomplished by the concept of equivalent material values (Bonacina and Comini, 1973). The idea is to operate with strong temperature-dependent material values within the phase range, that is, to include the enthalpy of phase changes $\left(\Delta h_{\text {mett }}\right)$ within the capacity density $\tilde{c}=\rho c$. Figure 5 shows this relation graphically.

Whereas the change in material values in a continuous phase transition may be determined only by measurement, an abrupt phase transition
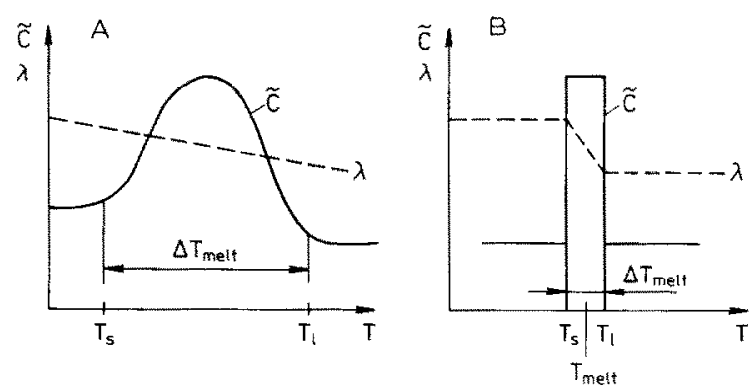

Fig. S. Enthalpy of the phase transition for continuous (A) and abrupt (B) conditions (see text for explanation). 
may be simulated using the values of the melt enthalpy of the pure phases:

$$
\begin{aligned}
& \tilde{c}\left\{\begin{array}{l}
=\tilde{c}_{\mathrm{s}} \ldots \text { for } T<T_{\text {melt }}-\frac{\Delta T_{\text {melt }}}{2} \\
=\frac{\Delta \tilde{h}_{\text {melt }}}{\Delta T_{\text {melt }}}+\frac{\tilde{c}_{\mathrm{s}}+\tilde{c}_{1}}{2} \ldots
\end{array}\right. \\
& \text { for } T_{\text {melt }}-\frac{\Delta T_{\text {melt }}}{2} \leq T \leq T_{\text {melt }}+\frac{\Delta T_{\text {melt }}}{2} \\
& =\tilde{c}_{1} \ldots \text { for } T>T_{\text {melt }}+\frac{\Delta T_{\text {melt }}}{2} \\
& \lambda\left\{\begin{array}{c}
=\lambda_{\mathrm{s}} \ldots \text { for } T<T_{\text {melt }}-\frac{\Delta T_{\text {melt }}}{2} \\
=\lambda_{\mathrm{s}}+\frac{\lambda_{\mathrm{s}}+\lambda_{1}}{\Delta T_{\text {melt }}}\left[T-\left(T_{\text {melt }}-\frac{\left.\left.\Delta T_{\text {melt }}\right)\right] \ldots}{2}\right)\right] \\
T_{\text {melt }}-\frac{\Delta T_{\text {melt }}}{2} \leq T \\
\text { for } T_{\text {melt }}+\frac{\Delta T_{\text {melt }}}{2} \leq T \\
=\lambda_{1} \ldots \text { for } T>T_{\text {melt }}+\frac{\Delta T_{\text {melt }}}{2}
\end{array}\right.
\end{aligned}
$$

index "s" = solidus, index "l" = liquidus.

For the numerical calculations the model of abrupt phase transition was chosen, but the application is somewhat problematical because of unknown material values. The value of the enthalpy of melting for granite, taken from Kaspar et al. (1984), undoubtedly is too high as it was determined under ambient conditions. The following valucs wcre used for calculations:

$\lambda_{\mathrm{s}}=\lambda_{1}=2.93 \mathrm{~W} / \mathrm{mK}$

$\rho=2750 \mathrm{~kg} / \mathrm{m}^{3}$

$\tilde{c}_{\mathrm{s}}=c_{1}=2.93 \cdot 10^{6} \mathrm{~J} \mathrm{~kg}^{-1} \mathrm{~K}^{-1}$

$\Delta h_{\text {melt }}=165.7 \mathrm{~kJ} / \mathrm{K}$

$T_{\text {melt }}=700^{\circ} \mathrm{C}$

$\Delta T_{\text {melt }}=10 \mathrm{~K}, 100 \mathrm{~K} \ldots$

$T_{\mathrm{I}}=T_{\text {melt }}+\Delta T_{\text {melt }} / 2$

\section{Mathematical approximation}

The solution of the Fourier equation is given by means of the finite element method. The starting point is the formulation of a principle of variation which is determined approximately by Ritzian trial functions over partial domains (finite elements). For the stationary state the limiting functional reads (Fischer et al., 1985):

$$
\begin{aligned}
\kappa= & \int_{v} \frac{1}{2}\left[\lambda_{x}\left(\frac{\partial T}{\partial x}\right)^{2}+\lambda y\left(\frac{\partial T}{\partial x}\right)^{2}+2 T \dot{q}\right] \mathrm{d} v \\
& +\oiint(\ldots) \mathrm{d} A
\end{aligned}
$$

whereby the surface term $\oiint \ldots \mathrm{d} A$ includes the boundary conditions. The variational calculation leads to the solution of a system of algebraic equations of the form:

$[k]\{T\}=\{F\}$

in which the vector $\{T\}$ contains the desired temperatures within the nodes of the elements. The conductivity matrix $[k]$ contains mainly the contributions of heat conduction, but the contributions of the sources and boundary conditions enter the residual vector $\{F\}$. Instationary processes are covered by a successive execution of stationary states, resulting in a system of equations of the form:

$[c] \frac{\mathrm{d}}{\mathrm{d} t}\{T\}+[k]\{T\}=\{F\}$

which will be reduced again to the original type (13) after time integration.

The numerical calculation was done using the FORTRAN program T84 (Fischer et al., 1985). This program is based on triangular elements with quadratic starting point functions. The network of the basic region consists of an equidimensional grid with a maximum of 200 triangular elements and is shown partly in Fig. 6. The time integration was done by an implicit one-step procedure. As a

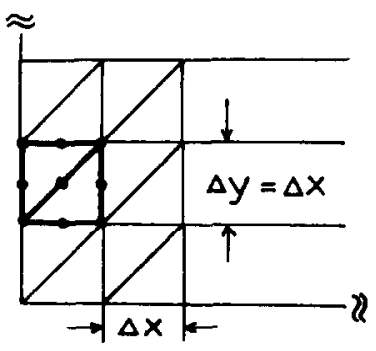

Fig. 6. The basic construction of the grid for the numerical calculation procedure. 

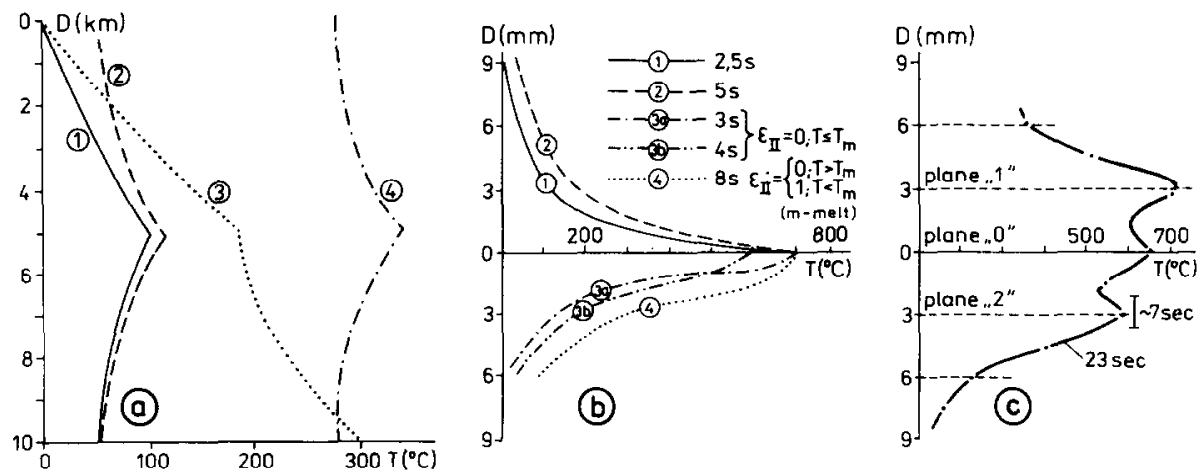

Fig. 7. Results of simulations for the case of (a) "stable gliding" (b) "stick-slip", (c) stick-slip combined with a trigger mechanism (see text for explanations).

guiding value for the time- and space-discretisation the Binder-Schmidt criterion was chosen:

$\Delta t>\frac{\rho c(\Delta x)^{2}}{2 \lambda}$

The iteration for temperature follow directly within each time interval. The system of equations is solved using the "front-solution method".

\section{Results}

From a large number of calculations, determined for the case of stable gliding primarily from the boundary conditions and the total displacement, but in the case of "stick-slip" from the source distribution (the boundary conditions being of little importance, due to the small penetration of the temperature wave), we present some representative results. Simplified physical assumptions, uncertain material values and compromises, necessary for reasonable computing expense, give the calculations the character of numerical experiments, which, while unsuitable for exact quantifi-

TABLE 1

Limiting conditions for stable gliding simulations (Fig. 7a)

\begin{tabular}{lllcc}
\hline $\begin{array}{l}\text { Curve } \\
\text { No. }\end{array}$ & $\begin{array}{l}\text { Initial temp., } \\
T_{0}\left({ }^{\circ} \mathrm{C}\right)\end{array}$ & \begin{tabular}{l} 
Surface temp. \\
\cline { 3 - 5 }
\end{tabular} & $\left.\begin{array}{l}\text { Total dis- } \\
\text { placement, } \\
D(z=0)\end{array}\right)$ & $T(z=10)$ \\
\hline$I$ & 0 & 0 & - & 25 \\
2 & 0 & - & - & 25 \\
3 & linear $(0,300)$ & 0 & 300 & 25 \\
4 & 0 & - & - & 100 \\
\hline
\end{tabular}

cation, allow trends and possibilities to be suggested.

\section{Stable gliding}

Figure $7 \mathrm{a}$ shows the temperature versus depth dependence of a $10 \mathrm{~km}$-thick granite plate, resulting from different boundary and initial conditions. The shear plane lies at a depth of $5 \mathrm{~km}$, the velocity is $5 \mathrm{~cm} / \mathrm{yr}$. Table 1 summarizes the assumed limiting conditions.

Cases where boundary temperatures are not fixed correspond to an adiabatic limitation, i.e. that heat flow is set to zero. From curves 2 and 4 it is clear that there is only a minimal increase in temperature in the shear zone. The absolute value of the temperature maximum in the shear zone depends on the assumed boundary conditions and initial temperature. Curve 3 is based on a geothermal gradient of $30^{\circ} \mathrm{C} / \mathrm{km}$.

From the temperature curves it becomes obvious, that, for geologically realistic displacements, the mechanism of stable gliding does not allow the conditions of melting to be reached.

\section{Stick-slip mechanism}

In contrast to the case of stable gliding, where the boundary and initial conditions influence the temperature profile, these conditions are unimportant regarding the stick-slip process, as the energy release occurs shock-like and there is no possibility of the temperature wave propagating. 
TABLE 2

Results of a one-dimensional estimation of the time regime for the stick-up mechanism*

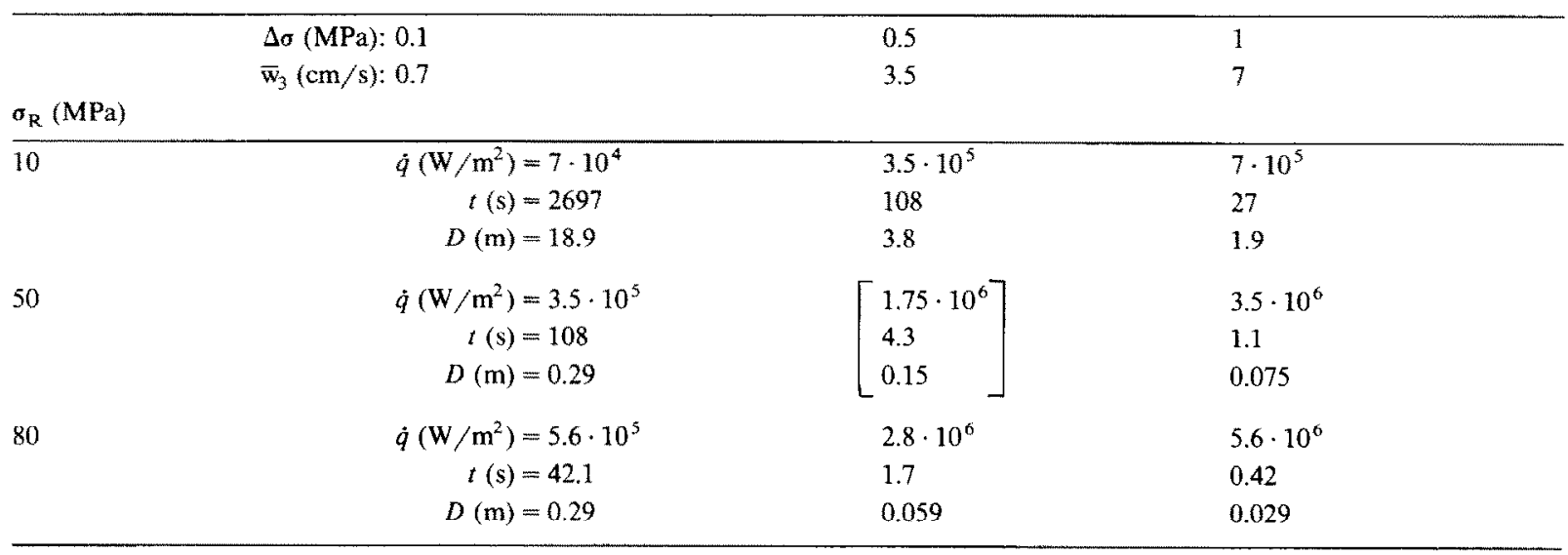

* The values between brackets are used in subsequent calculations.

To estimate the time frame and the expected displacements we used the one-dimensional analytical solution given by McKenzie and Brune (1972) and Aki (1979), giving:

$t \approx\left(\frac{\rho v_{i} T_{\text {melt }}}{0.64 \delta \cdot \Delta \delta}\right)^{2} \pi \lambda \rho c$

Table 2 contains the calculated values (eqn. 15) for times $t$, displacements $D$, and source intensities $\dot{q}(\eta=1)$, required for attainment of a melting temperature $T_{\text {melt }}=700^{\circ} \mathrm{C}$.

It is clear from this summary of parameters that the time for reaching the conditions of melting becomes very short with increasing shear stress reduction $\Delta \delta$, and that the thickness of melt zones will be very restricted.

The set of parameters between brackets in Table 2 was used for the numerical modelling. On the basis of conditions given by the one-dimensional estimation, we can draw some conclusions as to trends from other, different sets of parameters.

Figure $7 \mathrm{~b}$ shows temperature profiles at different times over a shear plane. The upper half depicts the distributions up to the melting temperature for a constant efficiency (curve 1) and an efficiency exponentially dependent on temperature (curve 2). The lower part of Fig. $7 \mathrm{~b}$ shows the effect of time regime II. Curves $3 a$ and $3 b$ show the degenerate hehaviour $\epsilon_{\mathrm{II}}=0$ for $T \leq T_{\text {metl }}$ ), while curve 4 represents the simulation of a trigger mechanism: $\epsilon_{11}=0$ for $T>T_{\text {melt }}$ and $\epsilon_{\mathrm{II}}=1$ for $T<T_{\text {melt }}$. The temperature paths indicate that a melt zone on the millimetre scale exist around the shear plane. To explain wider melt zones under retention of the stick-slip mechanism, it must be assumed that immediately adjacent planes are brought into the process, whereby the energy relcasc occurs cascade-like by jumping to the adjacent planes. Figure $7 \mathfrak{C}$ shows such a process for three participating planes, $3 \mathrm{~mm}$ apart. After the phase temperature is reached on plane $O$ plan $I$ will be activated and with beginning of melting on plane 1 , plane 2 comes into play. For the temperature dependency of the efficiency formulation $9 \mathrm{~d}$ is used, because this formulation satisfies the requirement $\eta=0$ for $T=t_{\mathrm{l}}$. The temperature interval of the phase change is chosen to be 100 $\mathrm{K}=\Delta T_{\text {melt }}$. The foregoing process leads to wider melt zones and may be regarded thermodynamically as an effective mechanism. Nevertheless the activation of adjacent planes occurs randomly and is not necessitated by a mechanical model.

On the other hand, the proposed model addresses concepts derived from geological observations. It concerns not only the "jump time" of activation of the planes but also the correlation between the observed widths of melt zones (frictionites) and those of the energetically favourable regions of the fold structure, namely parallel 
orientation of several (at least two) schistosities in the inverted fold limbs. The model explains further the sporadical distribution of frictionites along the shear plane, which results from the geologically, thermodynamically and mechanically somewhat restricted boundary conditions for melt generation.

The proposed model is supported by geological field observations: There is no fault or shear zone composed of a single plane. They are zones composed of plenty of planes, different in their extent and jumping in space within the zone and different in time regarding their activation too. These features are proved by earthquake observations: An earthquake can consist of a temporal and spatial succession of several events, depending on the physical conditions within the fault zone (asperity- and barrier-models). In general there is no repeated activation of an already moved plane (see the distribution of hypocenters).

\section{Conclusions}

Application of the foregoing physico-mathematical model of heat generation by friction along shear planes leads to the following conclusions:

(1) The "stable gliding" mechanism can be excluded as an effective process for the geological situation at hand. The attainable temperatures are far below the melting temperature for geologically realistic displacements.

(2) A stick-slip mechanism leads rapidly to the beginning of melting and may be regarded as a viable process. The width of the resulting molten zone, however, amounts to no more than a few millimetres at each shear plane.

(3) Wider melt zones may be accounted for by a cascade-like propagation of the activation of adjacent shear planes, whereby the activation of single planes may take place simultaneously or in rapid succession.

This trigger-mechanism is supported by geological field evidences: multi-surface, jump-like activation of zones in fold structures, sporadic distribution of thin melt zones (frictionites) along the shear planes, small thickness (volume) and a good correlation between width of the melt zone and that of the energetically favourable zone in the fold structure.

(4) The random source distribution assumed by the model, which from a thermal standpoint should allow wider melt zones, needs verification by a suitable mechanical model that also takes into account the temperature dependence of the material properties.

\section{Acknowledgements}

We thank Dr. Thomas Frisch, Ottawa (Canada), for a critical review of an early draft of the manuscript.

\section{References}

Aki, K., 1979. Characterization of Barriers on an Earthquake Fault. J. Geophys. Res., 84: 6140-6148.

Bonacina, C. and Comini, G., 1973. On the solution of the nonlinear heat conduction equations by numerical methods. Int. J. Mass. Transfer., 16: 581-589.

Brewer, J., 1981. Thermal effects of thrust faulting. Earth Plant. Sci. Lett., 56: 233-244.

Fischer, S., Hänisch, M., Seidel, M. et al., 1985. Berechnung von Feldproblemen mit Hilfe der Methode der finiten Elemente. Energietechniki, 35: 463-469.

Frischbutter, A., 1982. Zur Deformation der prävariszischen Granite des mittleren Erzgebirges. Veröff. Zentralinst. Phys. Erde Potsdam, 72: 75-88.

Frischbutter, A., 1985. Zur geologischen Entwicklung der Reitzenhainer Rotgneisstruktur. Freiberger Forsch. H., C390: 29-44.

Frischbutter, A. and Just, G., 1988. Zur stofflichen Entwicklung der Reitzenhainer Rotgneisstruktur auf der Grundlage aktivierungs-analytischer Bestimmungen seltener Elemente. Geophysik und Geologie, Geophys. Veröff. K.M.U., Leipzig, IV: 75-92.

Frischbutter, A., 1990. Prävariszische Granitoide der Fichtelgebirgisch-Erzgebirgischen Antiklinalzone und ihre Bedeutung für die Krustenentwicklung am Nordrand des Böhmischen Massivs. Veröff. Zentralinst. Phys. Erde Potsdam, 69: $153 \mathrm{pp}$.

Frischbutter, A., Thomas, R. and Tauber, F., 1989. Thermobarometrische Untersuchungen an Flüssigkeitseinschlüssen in Quarz zum Problem des Deformationsablaufes in unterschiedlichen Krustentiefen am Beispiel der Reitzenhainer Rotgneisstruktur. Z. Geol. Wiss., 17: 1041-1052.

Holdaway, M.J., 1971. Stability of andalusite and the aluminosilicate phase diagram. Am. J. Sci., 271: 97-131.

Kaspar, G., Peehs, M. and Höpfel, R., 1984. Experimentelle Bestimmung der intergralen Schmelzenthalpie von Bunt- 
sandstein, Granit Schiefer, Schmeltzbasalt, $\mathrm{Al}_{2} \mathrm{O}_{3}$ und $\mathrm{MgO}$. High Temp. High Pressures, 16: 21.26.

Luth, W., Jahns, R. and Tuttlle, O.F., 1964. The granite system at pressure of 4 to 10 kilobars. J. Geophys. Res., 69 : $759-773$.

McKenzie, D. and Brune, J.N., 1972. Melting on fault planes during large earthquakes. Geophys. J. R. Astron. Soc., 29: $65-78$.

Ohnaka, M., 1978. Application of some dynamic properties of stick-slip to earthquakes. Geophys. J. R. Astron. Soc., 53: 311-318.

Pavlis, T.L., 1986. The role of strain heating in the evolution of megathrusts. J. Geophys. Res., 91: 12407-12422.
Scheumann, K.-H., 1938. Über die petrographische und chemische Substanzbestimmung der Gesteinsgruppen der Roten Gneise des sächsischen Erzgebirges und der angrenzenden Räume. Mineral. Petrogr., N.F., 50: 391-440.

Stettner, G., 1971. Orogene Schollentektonik und granitoide Mobilisation im Westteil der Böhmischen Masse. Geol. Rundsch, 60: 1465-1487.

Stettner, G., 1972. Die geotektonische Entwicklung im Westteil der Böhmischen Masse bei Berücksichtigung des Deformationsstils in orogenen Bewegungssystemen. Z. Dtsch. Geol. Ges., 123: $561-574$.

Winkler, H.G.F., 1974. Petrogenesis of Metamorphic Rocks. Springer, Berlin, 320 pp. 